\title{
Project LIFE—Learning to Improve Fitness and Function in Elders: Methods, design, and baseline characteristics of randomized trial
}

\author{
Miriam C. Morey, PhD; ${ }^{1-2 *}$ Matthew J. Peterson, PhD; ${ }^{1-2}$ Carl F. Pieper, DrPH; ${ }^{2}$ Richard Sloane, MS; ${ }^{2}$ Gail M. \\ Crowley, MSN, RN, ANP-C; ${ }^{1-2}$ Patricia Cowper, PhD; ${ }^{2}$ Eleanor McConnell, PhD; ${ }^{1-2}$ Hayden Bosworth, PhD; ${ }^{2-3}$ \\ Carola Ekelund, PT; ${ }^{1}$ Megan Pearson, MA; ${ }^{1}$ Teresa Howard, AA ${ }^{\mathbf{1}}$ \\ ${ }^{1}$ Durham Department of Veterans Affairs Medical Center (VAMC), Geriatric Research, Education, and Clinical Center, \\ Durham, NC; ${ }^{2}$ Duke University Medical Center, Aging Center, Durham, NC; ${ }^{3}$ Durham VAMC, Health Services Research \\ and Development Service, Durham, NC
}

\begin{abstract}
Insufficient levels of physical activity have significant clinical consequences. Primary care settings typically do not emphasize physical activity counseling. We describe the design, methods, and baseline characteristics of "Learning to Improve Fitness and Function in Elders," a two-armed randomized controlled trial that assesses whether physical activity counseling improves the physical function of older veterans. A physical activity counseling program, partially administered by primary care providers, advocating 30 min of walking 5 days a week and 15 min of lower-limb strength training 3 days a week will be compared with usual care. The multicomponent counseling program consists of yearlong (1) telephone counseling, (2) automated and in-person provider counseling, and (3) tailored mailed materials. Physical activity will be assessed with the Community Healthy Activities Model Program for Seniors. Physical function will be assessed by gait speed (primary end point), $400 \mathrm{~m}$ walk time, chair stands, balance tests, and self-reported physical function and disability. Self-reports of chronic illness, symptoms, pain, health-related quality of life, self-efficacy, and motivation will also be assessed. A total of 400 veterans, aged 70 to 92 , have enrolled and are currently receiving multicomponent physical activity counseling or usual care.
\end{abstract}

Clinical Trial Registration: Life 2: Improving Fitness and Function in Elders, clinical trial registration NCT00435188, $<$ www.clinicaltrials.gov $>$.

Key words: aging, behavioral counseling, cost analysis, disability, health promotion, mobility limitations, physical activity, primary care, randomized clinical trial, rehabilitation, veterans.

\section{INTRODUCTION}

Most older adults are not regularly physically active [1]. Physical inactivity is associated with increased rates of morbidity, functional limitations, disability, and mortality. Concurrent with this finding are the continued reports of low numbers of individuals engaging in physical activity of sufficient stimulus to achieve a health benefit. Increasing physical activity is fundamental to prevention and treatment of physical limitations and many chronic diseases [2].

Low physical activity is highly associated with increased functional decline [3]. Difficulty walking, climbing stairs, performing usual daily tasks, and increasing

Abbreviations: $\mathrm{ACT}=$ Activity Counseling Trial, ANOVA $=$ analysis of variance, CHAMPS = Community Healthy Activities Model Program for Seniors, DSS = Decision Support System, LIFE $=$ Learning to Improve Fitness and Function in Elders, MOS SF-36 $=$ Medical Outcomes Study 36-item Short Form (Health Survey), NIA = National Institute on Aging, PCP = primary care provider, $\mathrm{QOL}=$ quality of life, $\mathrm{RCT}=$ randomized controlled trial, VA $=$ Department of Veterans Affairs, VAMC = VA medical center.

* Address all correspondence to Miriam C. Morey, PhD; Durham VAMC, GRECC, 182, 508 Fulton St, Durham, NC 27705; 919-286-0411, ext 6776; fax: 919-286-6823.

Email: morey@geri.duke.edu

DOI: 10.1682/JRRD.2007.03.0044 
social isolation are all hallmarks of functional decline [4-5]. This association is well documented and is independent of the presence of chronic illnesses [6-8]. Additionally, low physical activity is considered a primary marker of physical frailty, which predicts subsequent disability [9].

Interventions targeting physical inactivity in older adults are especially important given that rates of physical inactivity are highest among older adults, healthcare costs are higher among inactive than active adults, and the prevalence of chronic disease and disability increases with age [10]. Older veterans are of particular interest because they typically report significantly more physical difficulties than nonveterans [11] and about 50 percent of veterans over age 74 have a limiting disability [12].

Project LIFE—Learning to Improve Fitness and Function in Elders-is a randomized controlled trial (RCT) designed to assess whether physical activity counseling will increase physical function in older veterans who are being followed by Department of Veterans Affairs (VA) primary care and geriatric clinics. Project LIFE creates a unique partnership between the veteran, his/her primary care provider (PCP), and a health counselor through the innovative use of automatic telephone messaging. The primary care setting is ideal for this study because more than 90 percent of older adults visit their PCP at least once a year [13]. Older veterans with multiple chronic illnesses typically see their PCPs more frequently.

In this article, we describe the design, methods, and baseline characteristics of Project LIFE. Its specific objectives are to determine (1) whether a multicomponent physical activity counseling program versus usual care improves physical function, with change in gait speed as the primary indicator of functional status; (2) whether this program results in significant changes in minutes per week of endurance and lower-limb strengthening physical activity; (3) whether this program secondarily promotes changes in other measures of physical performance (400 m walk time, chair stands, balance tests), self-reports of physical function, chronic illness, symptoms, pain, healthrelated quality of life (QOL), physical activity, self-efficacy, and motivation; and (4) the cost of the intervention. We also want to compare inpatient and outpatient healthcare costs in the two groups during the study period to establish the short-term economic impact of the proposed multicomponent physical activity counseling program.

\section{METHODS}

Project LIFE is a two-armed RCT conducted in primary care clinics at the Durham VA medical center (VAMC) in North Carolina. Individuals randomized to the intervention group receive a physical activity counseling intervention with five components: (1) in-person baseline physical activity counseling session tailored to the veteran's personal functional goals and limitations; (2) systematic telephone follow-up by the health counselor; (3) systematic automated telephone calls from the veteran's PCP; (4) PCP endorsement of physical activity during a clinic visit; and (5) individually prepared progress reports, mailed quarterly, summarizing achievement of physical activity goals. Each component of the intervention builds on existing literature on determinants and promotion of physical activity that is primarily organized along a social cognitive theoretical framework [14]. Individuals randomized to the control group will receive usual care for 1 year. After completing study requirements, individuals in the usual care group will be offered an optional 3-month intensive, but reduced, version of the intervention. This service is offered to the usual care patients and is not considered part of the trial.

\section{Inclusion/Exclusion Criteria and Recruitment Process}

A two-step process of evaluations against inclusion/ exclusion criteria determines study eligibility. As a first step, our study personnel broadly review the medical records of patients aged 70 and over for exclusion criteria. Patients must be free of the following: a terminal diagnosis, unstable angina, history of ventricular tachycardia, chronic obstructive disease requiring two hospitalizations within the previous 12 months, uncontrolled hypertension, stroke with moderate-to-severe aphasia, diagnosis of chronic pain, active substance abuse, diagnosis of mental or behavioral disorder, dementia, severe hearing loss, or severe visual loss. In addition, potential participants must be able to walk $30 \mathrm{ft}$ without human assistance and be sedentary, which is defined as engaging in less than 150 min of physical activity a week. Medical records frequently do not include sufficient detail for personnel to determine whether an individual meets study criteria; for example, determining walking, hearing, or visual status from the medical record is difficult. For the second step, an introductory letter from the PCP introduces our research project to potential patients. This letter is sent to each PCP along with a copy of our exclusion criteria. The PCP is asked to determine the final 
eligibility using our exclusion criteria. For approved patients, the PCP signs the introductory letter and returns it to our office for mailing. For excluded patients, the letter is returned unsigned to our office with a notation of the particular criteria used for exclusion.

We then send out two packets to potential study participants. The first consists of the introductory PCP letter, which is very brief and simply states: "You will soon receive detailed materials about Project LIFE. Project LIFE is a health and physical activity counseling research project being conducted at the Durham VAMC. Your participation in Project LIFE is entirely voluntary. Please feel free to contact me if you have any questions regarding Project LIFE before your next clinic appointment with me.” The intent of the letter is to introduce the project to patients in a noncoercive manner. A separate recruitment package includes a detailed description of the study, consent forms, and a stamped postcard, giving the patients the opportunity to declare themselves interested or not interested. Individuals who express interest in the study or who fail to return the postcard are contacted by telephone as the final recruitment effort.

Randomization occurs on the initial visit to the VA, during which written consent and baseline measures are obtained. Randomization is computer-generated in blocks of eight. All researchers except the statistician are blinded to the randomization. Randomization assignments are kept in sealed envelopes and locked in the project coordinator's office until they are to be used.

In addition to the consent process, individuals complete a physical performance test and a computer-assisted selfreport of physical function, disability, symptoms, comorbidities, and health-related QOL. The entire visit lasts approximately $90 \mathrm{~min}$ and is repeated at 3, 6, and 12 months. Individuals blinded to the participant's randomization status administer all tests.

\section{Theoretical Framework for Physical Activity Intervention}

The core components of our intervention are based on the theoretical constructs developed for the Activity Counseling Trial (ACT), which was a landmark clinical trial promoting physical activity in primary care settings [15]. The ACT intervention was designed with the use of empirically tested models and theories of health-behavior change. Its primary theoretical basis relied heavily on social cognitive theory, in which behavior influences and is influenced by within-person factors and factors in the social and physical environment. The primary intervention strategy was designed to enhance self-efficacy, which is known to be an important predictor of physical activity [16]. Facets of social cognitive theory integrated into our intervention include modeling, self-monitoring, goal setting, reinforcement, and cognitive reframing, which are accepted as effective means of promoting change in physical activity [14]. We also use elements of the transtheoretical model "stage of change" concept as a guide to select appropriate intervention material for individuals based on their motivation and readiness to change behavior [17].

\section{Intervention Delivery and Materials}

\section{Baseline Counseling}

Individuals randomized to the intervention group meet initially with the health counselor for a baseline activity counseling session. The advantage of in-person counseling is that it gives the counselor a realistic picture of the client's functional status, which often diverges from impressions based on the client's medical record and selfreport. Baseline counseling uses a structured protocol, "Planning the First Step," that was developed for Project LIFE and adapted from the Physician-Based Assessment and Counseling for Exercise Project [18-19]. The baseline counseling is designed to be relatively brief and establish a realistic and structured starting point for engaging in physical activity. All individuals receive a workbook that includes the National Institute on Aging (NIA) exercise workbook ("Exercise: A Guide from the NIA"), elastic bands of different resistances with instructions for use, an exercise poster depicting six key lower-limb strength exercises, and a pedometer. They also practice walking purposefully to assess the accuracy of the pedometer and practice the leg-strengthening exercises.

\section{Telephone Counseling}

Each individual receives three follow-up telephone calls within the first 2 months and one every month thereafter. Each telephone call follows a specific protocol for each contact that consists of the following seven steps: (1) review profile prior to contact, (2) greet veteran and state purpose of contact, (3) assess physical activity goals and quantify physical activity completed in terms of stated goals, (4) offer support and reinforcement, (5) discuss barriers and problem solve, (6) set new physical activity goals, and (7) conclude. To encourage sustained physical activity, the counselor incorporates elements of social cognitive theory that enhance self-efficacy by reinforcing the importance of continued activity, identifying 
strategies to overcome barriers, and identifying individually feasible physical activities. The counselor identifies motivators and barriers and focuses on creating an environment and attitude conducive to becoming more physically active.

\section{Endorsement of Project Life by Primary Care Provider}

At the primary care clinical visit closest to the baseline session (visits occur on average every 3 or 4 months in this population), the PCP is sent an electronic reminder to acknowledge enrollment in Project LIFE and to endorse the exercise prescription.

\section{Automated Telephone Encouragement by Primary Care Provider}

An automated telephone call facilitates interface between the patient and the PCP without using valuable clinician time. Dubbert and colleagues found automated telephone calls to be a successful adjunct to physical activity counseling in a recently completed RCT for older adults at a Veterans Health Administration primary care clinic [20]. Each provider records a message of encouragement: "Hello! This is Dr. Goodworks from the Durham VAMC. I am so glad that you are participating in Project LIFE! I know that <insert health counselor's name> is helping you move along and I really hope that you're doing well with your program! Again, thank you for your participation-you are an important part of this study and your health is important to me!” We have reviewed the literature pertaining to telephone counseling and physical activity [21]. To the best of our knowledge, this is the first study where the PCP provides the telephone prompts endorsing physical activity.

\section{Mailed Materials}

To provide participants with visual reinforcement and printed motivational messages, we mail participants a tailored progress report every 12 weeks. The progress report consists of a two-page letter of encouragement and feedback. The first page is a cover letter that includes a paragraph tailored specifically to whether the individual has progressed toward the two study goals, endurance and strength. We developed eight tailored messages that addressed all possible scenarios: improvement toward both goals, improvement in one goal but not the other, achievement of maintenance for either goal, failure to improve, or a decrease from previous record. The second page consists of two graphs depicting quarterly progress toward each goal.

\section{Measures}

\section{Physical Performance}

Gait speed is derived from an $8 \mathrm{ft}$ walk test with the use of a Speedtrap II wireless timing system (MF Athletic Co; Cranston, Rhode Island) that records walking time with 1/100 s accuracy. The Speedtrap II consists of two sets of infrared sensors placed $8 \mathrm{ft}$ apart that are motion activated. Starting approximately $2 \mathrm{ft}$ from the sensors, individuals are asked to walk at their normal pace until prompted to stop about $2 \mathrm{ft}$ past the sensors. They turn around and are prompted to walk back as fast as possible. This task is repeated to produce two trials of usual and fast walking speed with the fastest value for each task recorded for scoring purposes. Other tests of physical performance include three tests of standing balance and five chair stands, as described by Guralnik and colleagues, which, combined with usual gait speed, are used to calculate the score for the Short Physical Performance Battery [22]. Scoring ranges from 0 to 12, with a higher score indicating better physical performance. Grip strength is measured with the selection of the best of three trials of preferred arm grip strength using a hand-held dynamometer. The final physical performance test is the $400 \mathrm{~m}$ corridor walk test as described by Simonsick and colleagues and developed for the Health, Aging, and Body Composition study [23].

\section{Self-Reported Quality of Life, Physical Function, and Disability}

We use several measures of self-reported function and disability to examine change specific to our proposed intervention: (1) four subscales of the Medical Outcomes Study 36-item Short Form (MOS SF-36) Health Survey: healthrelated quality of life, pain, vitality, and physical function [24-25]; and (2) the Late Life Function and Disability instrument, which was developed by Jette et al. and Haley et al. with the specific intent of being responsive to change in two distinct outcomes, function and disability [26-27]. All of these scales are scored by normalizing raw data and range from 0 to 100, with higher scores indicating better function and less disability.

\section{Physical Activity}

Physical activity is assessed with a modified version of the Community Healthy Activities Model Program for Seniors (CHAMPS) questionnaire [28]. The CHAMPS questionnaire provides two scores for analysis: (1) frequency per week of all physical activities and (2) calories 
per week expended in all physical activities. The CHAMPS questionnaire has good construct validity and reliability and is sensitive to change [28-30]. We altered the CHAMPS so that all activities are collected using minutes of reported activity as a continuous variable rather than the prespecified categorical variables described in the CHAMPS. This alteration enables us to capture small changes in minutes of physical activity. The particular advantage of the CHAMPS questionnaire for this study is that it was developed for older adults and has been tested with interventions using home-based programming.

\section{Significant Health Events}

We monitor changes in health status at each followup by asking specifically about significant life events, health changes, injuries, or falls. For each event, participants are asked to describe the nature of the event and to report whether the event required a visit to the doctor, emergency room, or hospitalization (VA or non-VA).

\section{Other Measures}

Personal health and fitness goals are derived from a modified personal functional goals tool [31]. Individuals are asked to choose a goal that reflects an expected benefit of being more physically active. They are then asked to place themselves on a ladder rating their perception of where they are at present on a scale from 1 to 10 . On follow-up, they are reminded of the goal and score and asked to reassess where they are on the ladder.

Self-efficacy is assessed as the confidence in the ability to walk 30 min on 5 or more days a week and do strength training for 15 min on 3 or more days a week. Exercise self-efficacy is an important predictor of exercise adherence [16]. Motivation to exercise is similarly assessed and is expressed as the desire to do the proposed exercise. Two questions were used: "How much do you want to do exercises for 15 minutes, 3 days a week, to make your legs stronger?" and "How much do you want to walk or do another type of endurance exercise for 30 minutes on 5 or more days of the week?”

\section{Intervention Costs}

Intervention costs consist primarily of healthcare counselor labor. Time associated with patient visits and telephone calls will be recorded prospectively by the healthcare counselor. In addition, the time spent by the counselor on all intervention-related clinical activities (versus research tasks) will be estimated using self- reported work sampling [32-33]. Type of clinical activity will be recorded for descriptive purposes. The work sampling will be conducted over several weeks during a stable period of the intervention. Estimates of time spent endorsing the intervention during clinic visits will be provided by physicians. The pilot study suggests that less than 3 min of physician time a visit is required. Labor time will be converted to costs with applicable salaries and fringe benefits. Additional costs incurred will be tracked with project expense records (e.g., supplies, automated call development, and telephone charges). The cost of office space used for the intervention will be based on outpatient costs in the Decision Support System (DSS) National Cost and Pharmacy Extracts.

\section{Healthcare Costs During Follow-Up}

We will estimate the costs associated with inpatient stays, outpatient clinics visits, emergency room encounters, outpatient diagnostic tests, and medications. The cost of VA healthcare services received by study patients will be obtained from the DSS National Cost and Pharmacy Extracts [34]. The national cost databases contain total, direct (fixed and variable), and indirect costs for inpatient and outpatient encounters. Costs are subdivided into major categories (laboratory, pharmacy, radiology, surgery, nursing, and other). The pharmacy extract contains direct cost and dosage details for outpatient prescriptions filled. Because the DSS extracts are relatively new, we will use the Medical Inpatient Databases and Outpatient Data Sets as confirmatory sources of resource use [35]. Healthcare received at non-VA facilities will be ascertained and recorded by the healthcare counselor during follow-up phone calls. We will request billing data for patient-reported non-VA hospitalizations to confirm the occurrence and nature of the hospitalizations. NonVA services will be valued using costs provided in the Health Economics Resource Center average cost data sets [36-37].

\section{Sample Size and Power}

We have chosen change in gait speed as our primary indicator of improved physical function because of the strong literature supporting gait speed as an important predictor of functional status [38]. We also characterize physical function with a rich battery of physical performance and self-reported tests but will declare the counseling trial a success only if we see a statistically significant change in gait speed. We have recruited a sample size of 400 that, 
given our assumptions of an equally divided sample and a two-tailed $\alpha=0.05$ and $\beta=0.20$, will give us 80 percent power to detect a standardized difference of 0.29 in the change scores in the intervention group relative to the control group. Effects of this magnitude are labeled "medium" in the statistical power literature [39]. In our pilot study, an interim analysis over 3 months for gait speed, we observed a standard deviation of $0.10 \mathrm{~m} / \mathrm{s}$ in the change of gait speed in the combined groups [40]. If the variance of change holds in the larger study over a longer period, we will have 80 percent power to detect differences between groups in the change in gait speed of $\sim 0.03 \mathrm{~m} / \mathrm{s}(0.1 \times 0.29)$-a relatively small difference in change. We believe that changes in gait speed as small as $0.10 \mathrm{~m} / \mathrm{s}$ are clinically meaningful because in another clinical trial with frail older veterans, each increase of $0.10 \mathrm{~m} / \mathrm{s}$ in gait speed was associated with two fewer rehabilitation visits, three fewer medical surgical visits, and lower hospitalization index costs [41].

\section{Data Analyses}

Repeated measures analyses will be used. Since some subjects will have missing data, we will use general estimating equation models [42], hierarchical linear models or random coefficients models [43], or mixed models analysis of variance (ANOVA) [44], which are appropriate for unbalanced data sets. These models extend the standard repeated measures ANOVA to allow for missing values, error structures other than compound symmetry, and measurements taken at nonequal intervals. We will assess the normality of the measures and residuals and, if possible, employ transformations to achieve approximate normality. Our general analytic strategy will be to employ these estimation models to assess (1) overall differences between groups and (2) differences in change over time between the groups. For this baseline article, we examined means and frequencies of the various outcomes without attention to randomization.

\section{RESULTS}

We recruited participants until we reached our targeted sample size, and 400 veterans are currently undergoing either the intervention (counseling) or usual care. As indicated in the Figure, patients were recruited from an initial medical record screening of 3,995 age-eligible veterans. Of these, 2,375 met initial study criteria and letters of introduction were sent to PCPs for final approval. One provider with 64 eligible patients withdrew from the study and 14 patients had no medical appointments during the enrollment period, leaving 2,297 patients eligible for PCP approval. From these, 1,917 (48\% of initial sample) were approved and recruitment packages were sent out. Telephone contact for enrollment was attempted for 1,567 patients, and 551 agreed to report for an initial enrollment visit. Of these, we obtained informed consent from and assigned randomization to 400 .

Data presented are from baseline (Table). Study participants were on average 78 years old and ranged from ages 70 to 92 . All but two were male, which reflects the relative paucity of female veterans in this particular age group. Forty-four percent reported some college or more advanced education, while 21 percent did not graduate from high school. Participants self-reported an average of five medical conditions, with hypertension (73\%), arthritis (65\%), heart conditions (47\%), diagnoses related to vision (40\%), circulation problems (38\%), and diabetes (34\%) the most prevalent. They also reported an average of six symptoms with shortness of breath with exertion (68\%), shortness of breath at rest (65\%), memory loss (52\%), problems with eyesight (51\%), balance problems (46\%), and numbness or tingling (44\%) the most prevalent.

Physical performance scores indicated below average physical functioning. The mean speed was $1.03 \mathrm{~m} / \mathrm{s}$ for usual walking speed and $1.56 \mathrm{~m} / \mathrm{s}$ for rapid gait, which were lower than the usual and rapid gait speeds of $1.3 \mathrm{~m} / \mathrm{s}$ and $2.0 \mathrm{~m} / \mathrm{s}$, respectively, reported for healthy older men in their seventies [45]. The Short Physical Performance Battery score, which combines gait speed with tests of balance and repeated chair stands, was 9.2. Only 36.8 percent of individuals rated their overall health-related QOL as very good or excellent. The mean self-report of physical function from the MOS SF-36 questionnaire was 65.4. Physical activity rates in our participant group were relatively low. Study participants averaged $37 \mathrm{~min}$ of walking or other endurance-related activities a week and only $20 \mathrm{~min}$ of strengthening activities a week.

\section{DISCUSSION}

Project LIFE is designed to provide an alternative approach to physical activity counseling that can be 


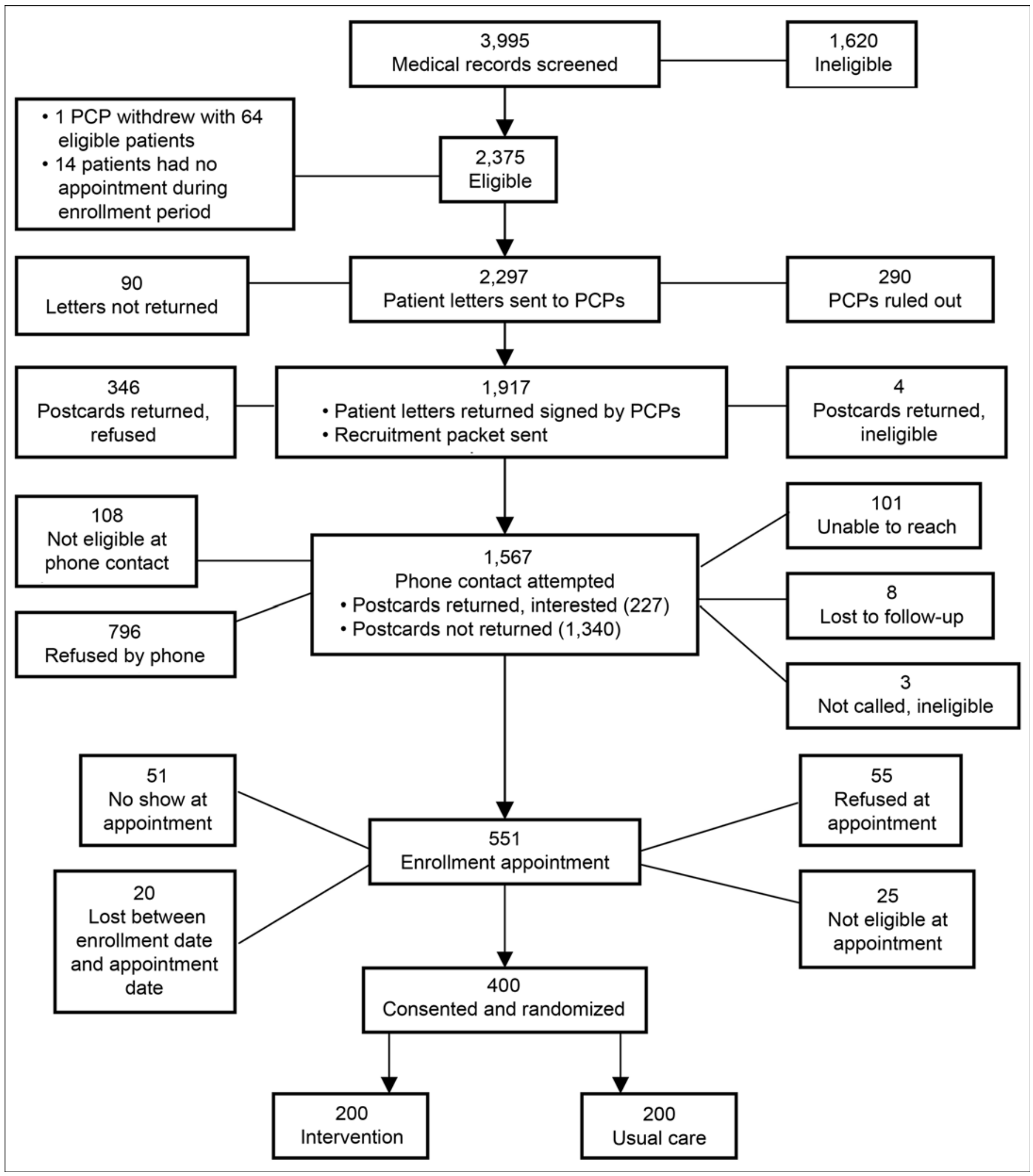

Figure.

Project LIFE—Learning to Improve Fitness and Function in Elders—participant flow chart. PCP = primary care provider. 
Table.

Baseline summary of participant characteristics.

\begin{tabular}{|c|c|c|}
\hline Demographic & $\begin{array}{c}\text { Mean } \pm \text { Standard Deviation } \\
\text { or Percentage }\end{array}$ & $N$ \\
\hline Age (yr) & $77.6 \pm 5.0$ & 400 \\
\hline Sex (\% male) & 99.5 & 400 \\
\hline Race (\% white) & 77.3 & 400 \\
\hline Education (\% some college or more) & 44.7 & 400 \\
\hline Self-Reported Diseases (No.) & $5.3 \pm 2.6$ & 400 \\
\hline Currently Using Assistive Devices (\%) & 20.3 & 400 \\
\hline \multicolumn{3}{|l|}{ Physical Performance } \\
\hline Gait Speed (usual m/s) & $1.03 \pm 0.24$ & 400 \\
\hline Gait Speed (rapid m/s) & $1.56 \pm 0.40$ & 400 \\
\hline Short Physical Performance Battery (range $0-12$, higher score $=$ higher function) & $9.2 \pm 2.1$ & 400 \\
\hline Health-Related Quality of Life (\% very good or excellent) & 36.8 & 400 \\
\hline Pain & $67.2 \pm 25.2$ & 400 \\
\hline Vitality & $57.0 \pm 21.0$ & 400 \\
\hline Physical Function & $65.4 \pm 22.7$ & 400 \\
\hline Late Life Function Score & $60.6 \pm 10.5$ & 400 \\
\hline Late Life Disability Score & $51.7 \pm 5.7$ & 400 \\
\hline \multicolumn{3}{|l|}{ Community Healthy Activities Model Program for Seniors (physical activity) ${ }^{\ddagger}$} \\
\hline Moderate Endurance Exercises (min/week) & $37.3 \pm 85.9$ & 396 \\
\hline Strengthening Exercises (min/week) & $21.4 \pm 50.4$ & 396 \\
\hline
\end{tabular}

seamlessly integrated into primary care. One advantage of this design is in the innovative use of automated telephone messaging, in which the PCPs can promote physical activity over an extended period of time with minimal personal effort and time. To our knowledge, we are the first to employ automated telephone messaging by PCPs in a program of this type [21].

The baseline physical activity patterns of the study group indicate that this is a worthy sample to target. The group's mean of 37 min a week spent in moderate endurance exercise was well below the recommended minimum weekly time of 150 min [46]. Further, less than half of the group (48.0\%) expressed confidence in being able to meet the current guidelines for weekly endurance exercise. We advocate lower-limb strengthening for maintained mobility; the average weekly time of $21 \mathrm{~min}$ spent in strengthening exercises of any intensity was approximately half of our long-term weekly goal of $45 \mathrm{~min}$ and perhaps not sufficient stimulus to offset loss of mobility. Additionally, although these data are not presented in the Table, only 13 percent of the group reported engaging in any strengthening exercises. This low proportion is consistent with 
population estimates of older men who engage in any strengthening exercises [47]. The theoretical underpinnings of behavior change for the intervention were supported by the low confidence in approximately 42 percent of the group to engage in sufficient weekly levels of strengthening exercises.

Given the low physical activity rates and other health characteristics of this sample, we are not surprised that our physical performance measures indicate individuals at high risk for adverse health outcomes. Our average gait speed would categorize individuals as "intermediate walkers," which was associated with higher 1-year hospitalization rates in a sample of Medicare users $(p<0.001)$ when compared with hospitalization rates of individuals with higher walking speeds [48]. Interestingly, the relationship between gait speed and 1-year hospitalizations did not hold true for veterans in the study because veterans had more hospitalizations across all walking speeds. In this same study, performance battery scores comparable with our sample mean were associated with more frequent hospitalization among the veterans $(p=0.01)$. In an analysis conducted on Health, Aging, and Body Composition study data, which is a longitudinal study of initially wellfunctioning elders, our average performance battery score and $400 \mathrm{~m}$ walk means fall within the lowest quartiles of their samples. Individuals in the lowest quartile of $400 \mathrm{~m}$ walk time had the highest 5-year mortality rate [49]. In terms of self-reported physical functioning, vitality, and pain, our mean scores are below the 50th percentile for men aged 65 and over [25].

We note the limitation that this study is directed at mostly white men living in North Carolina and Virginia, which may limit generalizability. However, we point out that the racial composition of this study is similar to the racial composition of the same age population in our surrounding counties. Perhaps of more importance is the fact that in the ACT, women were more successful then men in sustaining physical activity over the long term, and interventions directed at men with physical limitations are warranted [50].

\section{CONCLUSIONS}

A behavior change intervention that is based on the principles of social cognitive theory can potentially enhance physical activity and in turn ameliorate functional decline in a population that is already functionally compromised. We have included measures that will allow us to examine disability as an outcome distinct from functional decline. Our assumption is that enhancing confidence in the ability to make important lifestyle changes will facilitate behavior change. We believe that integration with the PCP will further facilitate this process. The healthcare utilization and examination of costs associated with this program, compared with usual care practices, will provide valuable information as the VA continues enhancing its efforts to promote health among veterans.

\section{ACKNOWLEDGMENTS}

We gratefully acknowledge the leadership and support of the many colleagues who facilitated this project: Dr. Harvey Jay Cohen for his constant leadership and enthusiastic support and Jennifer Chapman and Dee Carbuccia for their unflagging enthusiasm and hard work. We also gratefully acknowledge the participating PCPs who gave generously of their time: Nirmala M. Amaldoss, MD; Lori A. Bastian, MD; Charles Beauchamp, MD; Linda R. Bellefeuille, RN, NP; Cedric Bright, MD; Srobona T. Chatterjee, MD; Catherine M. Cone, PA-C; Rowena J. Dolor, MD; David Edelman, MD; Kenneth Goldberg, MD; Wendy O. Henderson, MD; Mahlon D. Grimsley, PA; Max A. Isbell, PA; Catherine P. Kaminetzky, MD; Sheri A. Keitz, MD; Sue Lander, ANP; David B. Matchar, MD; Douglas McCrory, MD; Carol D. McMorrow, PA-C; Robert R. Minton, PA-C; Thomas F. Newcomb, MD; Eugene Z. Oddone, MD; Lori A. Orlando, MD; Robert E. Peoples, PA; Susan M. Rakley, MD; India F. Reid, MD; Amy Rosenthal, MD; David L. Simel, MD; William F. Smith, PA; Jeannette F. Stein, MD; James Tulsky, MD; Ernest G. Daniels, MD; John D. Whited, MD; John W. Williams, MD; William S. Yancy Jr, MD; Diane Zimmerman, PA-C; Marisa D. Christensen, MD; Bill C. Logan, MD; Rajani Potu, MD; Pablo M. Rabosto, MD; William R. Knaack, MD; Susan Hastings, MD; and Katja Elbert-Avila, MD. Finally, we thank the numerous clinic nurses and appointment clerks, Heather Macdonald for her extensive programming and computer assistance, Lesa Hall for her design and media support, and the many kind veterans who enriched our lives and gave so generously of their time to participate in this research project.

This material was based on work supported by VA Rehabilitation and Research Development Service grant E3386R and NIA grants AG11268 and AG028716.

The authors have declared that no competing interests exist. 


\section{REFERENCES}

1. Centers for Disease Control and Prevention, National Center for Chronic Disease Prevention and Health Promotion [homepage on the Internet]. Promoting active lifestyles among older adults. Atlanta (GA): Centers for Disease Control and Prevention; c2002 (cited 2002 June 20). Available from:

http://www.cdc.gov/nccdphp/dnpa/physical/pdf/lifestyles.pdf

2. U.S. Department of Health and Human Services [homepage on the Internet]. Physical activity fundamental to preventing disease. Washington (DC): U.S. Department of Health and Human Services; c2002 (updated 2002 Jun 20; cited 2002 Jun 20). Available from:

http://aspe.hhs.gov/health/reports/physicalactivity

3. Miller ME, Rejeski WJ, Reboussin BA, Ten Have TR, Ettinger WH. Physical activity, functional limitations, and disability in older adults. J Am Geriatr Soc. 2000;48(10): 1264-72. [PMID: 11037014]

4. Fried LP, Bandeen-Roche K, Chaves PH, Johnson BA. Preclinical mobility disability predicts incident mobility disability in older women. J Gerontol A Biol Sci Med Sci. 2000;55(1):M43-52. [PMID: 10719772]

5. Unger JB, McAvay G, Bruce ML, Berkman L, Seeman T. Variation in the impact of social network characteristics on physical functioning in elderly persons: MacArthur Studies of Successful Aging. J Gerontol B Psychol Sci Soc Sci. 1999;54(5):S245-51. [PMID: 10542826]

6. Lawrence RH, Jette AM. Disentangling the disablement process. J Gerontol B Psychol Sci Soc Sci. 1996;51(4): S173-82. [PMID: 8673646]

7. DiPietro L. The epidemiology of physical activity and physical function in older people. Med Sci Sports Exerc. 1996;28(5):596-600. [PMID: 9148090]

8. Morey MC, Pieper CF, Cornoni-Huntley J. Physical fitness and functional limitations in community-dwelling older adults. Med Sci Sports Exerc. 1998;30(5):715-23.

[PMID: 9588614]

9. Fried LP, Tangen CM, Walston J, Newman AB, Hirsch C, Gottdiener J, Seeman T, Tracy R, Kop WJ, Burke G, McBurnie MA; Cardiovascular Health Study Collaborative Research Group. Frailty in older adults: Evidence for a phenotype. J Gerontol A Biol Sci Med Sci. 2001;56(3): M146-56. [PMID: 11253156]

10. Agency for Healthcare Research and Quality, Centers for Disease Control [homepage on the Internet]. Physical activity and older Americans: Benefits and strategies. Atlanta (GA): U.S. Department of Health and Human Services; c2007 (updated 2002 Jun; cited 2002 Jun 20). Available from: http://www.ahrq.gov/ppip/activity.htm

11. Gizlice Z. Health conditions and behaviors among North Carolina and United States military veterans compared to non-veterans. Raleigh (NC): State Center for Health Statistics; 2002.

12. Department of Veterans Affairs. National survey of veterans. Report No. P92493. Washington (DC): National Center for Veteran Analysis and Statistics; 1995.

13. National Center for Health Statistics. Health, United States, 2003. Washington (DC); Government Printing Office; 2003.

14. Marcus BH, King TK, Clark MM, Pinto BM, Bock BC. Theories and techniques for promoting physical activity behaviors. Sports Med. 1996;22(5):321-31. [PMID: 8923649$]$

15. King AC, Sallis JF, Dunn AL, Simons-Morton DG, Albright CA, Cohen S, Rejeski WJ, Marcus BH, Coday MC. Overview of the Activity Counseling Trial (ACT) intervention for promoting physical activity in primary health care settings. Activity Counseling Trial Research Group. Med Sci Sports Exerc. 1998;30(7):1086-96. [PMID: 9662678]

16. McAuley E, Elavsky S, Motl RW, Konopack JF, Hu L, Marquez DX. Physical activity, self-efficacy, and self-esteem: Longitudinal relationships in older adults. J Gerontol Psychol Sci Soc Sci. 2005;60(5):P268-75. [PMID: 16131621]

17. Prochaska JO, DiClemente CC. Stages of change in the modification of problem behaviors. Prog Behav Modif. 1992;28:183-218. [PMID: 1620663]

18. Patrick K, Sallis JF, Long B, Calfas KJ, Wooten W, Heath G, Pratt M. A new tool for encouraging activity. Phys Sports Med. 1994;22(11):45-52.

19. Project LIFE investigators. Project LIFE physical activity assessment and counseling protocols. Durham (NC); 2005. (updated 2005 Jan; cited 2005 Jan). Available from: http:// www.research.va.gov/resources/pubs/LIFE-modules.cfm

20. Dubbert PA, Cooper KM, Kirchner KA, Meydrech EF, Bilbrew D. Effects of nurse counseling on walking for exercise in elderly primary care patients. J Gerontol A Biol Sci Med Sci. 2002;57(11):M733-40. [PMID: 12403802$]$

21. Castro CM, King AC. Telephone-assisted counseling for physical activity. Exerc Sport Sci Rev. 2002;30(2):64-68. [PMID: 11991539]

22. Guralnik JM, Simonsick EM, Ferrucci L, Glynn RJ, Berkman LF, Blazer DG, Scherr PA, Wallace RB. A short physical performance battery assessing lower extremity function: Association with self-reported disability and prediction of mortality and nursing home admission. J Gerontol. 1994; 49(2):M85-94. [PMID: 8126356]

23. Simonsick EM, Montgomery PS, Newman AB, Bauer DC, Harris T. Measuring fitness in healthy older adults: The Health ABC Long Distance Corridor Walk. J Am Geriatr Soc. 2001;49(11):1544-48. [PMID: 11890597]

24. Ware JE Jr, Sherbourne CD. The MOS 36-item short-form health survey (SF-36). I. Conceptual framework and item selection. Med Care. 1992;30(6):473-83. 
25. Ware JE Jr, Snow K, Kosinski M, Gandek B. SF-36 health survey: Manual and interpretation guide. Lincoln (RI): QualityMetric Inc; 2000.

26. Jette AM, Haley SM, Coster WJ, Kooyoomjian JT, Levenson S, Heeren T, Ashba J. Late life function and disability instrument: I. Development and evaluation of the disability component. J Gerontol A Biol Sci Med Sci. 2002;57(4): M209-16. [PMID: 11909885]

27. Haley SM, Jette AM, Coster WJ, Kooyoomjian JT, Levenson S, Heeren T, Ashba J. Late life function and disability instrument: II. Development and evaluation of the function component. J Gerontol A Biol Sci Med Sci. 2002;57A(4): M217-22. [PMID: 11909886]

28. Stewart AL, Mills KM, Sepsis PG, King AC, McLellan BY, Roitz K, Ritter PL. Evaluation of CHAMPS, a physical activity promotion program for older adults. Ann Behav Med. 1997;19(4):353-61. [PMID: 9706362]

29. Stewart AL, Mills KM, King AC, Haskell WL, Gillis D, Ritter PL. CHAMPS physical activity questionnaire for older adults: Outcomes for interventions. Med Sci Sports Exerc. 2001;33(7):1126-41. [PMID: 11445760]

30. Mills KM, King AC, Stewart AL. Predictors of physical activity change in older adults (CHAMPS II): Preliminary results [abstract]. Gerontologist. 1998;38:394.

31. Bearon LB, Crowley GM, Chandler J, Robbins MS, Studenski S. Personal functional goals: A new approach to assessing patient-centered outcomes. J Appl Gerontol. 2000;19(3): 326-44.

32. Oddone E, Weinberger M, Hurder A, Henderson W, Simel D. Measuring activities in clinical trials using random work sampling: Implications for cost effectiveness analysis and measurement of the intervention. J Clin Epidemiol. 1995; 48(8):1011-18. [PMID: 7775988]

33. Harpole L, Stechuchak K, Saur C, Steffens D, Unutzer J, Oddone E. Implementing a disease management intervention for depression in primary care: A random work sampling study. Gen Hosp Psychiatry. 2003;25(4):238-45. [PMID: 12850655]

34. Yu W, Bennett P. Research guide to Decision Support System National Cost Extracts 1998-2003. Menlo Park (CA): Health Economics Resource Center, Health Services Research and Development Service, U.S. Department of Veterans Affairs; 2003.

35. Smith M, Barnett P, Phibbs C, Wagner T, Yu W. Micro-cost methods for determining VA health care costs. Menlo Park (CA): Health Economics Resource Center, Health Services Research and Development Service, U.S. Department of Veterans Affairs; 2003.

36. Wagner T, Chen S, Yu W, Barnett P. HERC'S inpatient average cost datasets for VA care version 3: Fiscal Years 1998-2001. Menlo Park (CA): Health Economics Resource
Center, Health Services Research and Development Service, U.S. Department of Veterans Affairs; 2002.

37. Phibbs C, Yu W, Lynn F, Barnett P. HERC's average costs datasets for VA Care: Fiscal Years 1998-2001. Menlo Park (CA): Health Economics Resource Center, Health Services Research and Development, U.S. Department of Veterans Affairs; 2003.

38. Guralnik JM, Ferrucci L, Pieper CF, Leveille SG, Markides KS, Ostir GV, Studenski S, Berkman LF, Wallace RB. Lower extremity function and subsequent disability: Consistency across studies, predictive models, and value of gait speed alone compared with the Short Physical Performance Battery. J Gerontol A Biol Sci Med Sci. 2000;55(4):M221-31. [PMID: 10811152]

39. Cohen J. Statistical analysis for the behavioral sciences. Revised edition. Hillsdale (NJ): Lawrence Erlbaum Associates; 1987.

40. Morey MC, Ekelund CC, Pearson M, Crowley G, Peterson MJ, Sloane R, Pieper C, McConnell E, Bosworth $\mathrm{H}$. Project LIFE: A partnership to increase physical activity in elders with multiple chronic illnesses. J Aging Phys Activ. 2006;14(3):324-43. [PMID: 17090809]

41. Purser JL, Weinberger M, Cohen HJ, Pieper CF, Morey MC, Li T, Williams GR, Lapuerta P. Walking speed predicts health status and hospital costs for frail elderly male veterans. J Rehabil Res Dev. 2005;42(4):535-46.

[PMID: 16320148]

42. Diggle P, Zeger SL, Lian KY. Analysis of longitudinal data. New York (NY): Oxford University Press; 1994.

43. Bryk AS, Raudenbush SW. Application of hierarchical linear models to assessing change. Psychol Bull. 1987;101(1): 147-58.

44. Laird NM, Ware JH. Random-effects models for longitudinal data. Biometrics. 1982;38(4):963-74. [PMID: 7168798]

45. Bohannon RW, Andrews AW, Thomas MW. Walking speed: Reference values and correlates for older adults. J Orthop Sports Phys Ther. 1996;24(2):86-90. [PMID: 8832471]

46. U.S. Department of Health and Human Services. Physical activity and health: A report of the Surgeon General. Atlanta (GA): U.S. Department of Health and Human Services, Centers for Disease Control and Prevention, National Center for Chronic Disease Prevention and Health Promotion; 1996.

47. Centers for Disease Control and Prevention. Strength training among adults aged 65 years-United States, 2001. MMWR Morb Mortal Wkly Rep. 2004;53(2):25-28. [PMID: 14737059]

48. Studenski S, Perera S, Wallace D, Chandler JM, Duncan PW, Rooney E, Fox M, Guralnik JM. Physical performance measures in the clinical setting. J Am Geriatr Soc. 2003; 51(3):314-22. [PMID: 12588574]

49. Newman AB, Simonsick EM, Naydeck BL, Boudreau RM, Kritchevsky SB, Nevitt MC, Pahor M, Satterfield S, Brach 
JS, Studenski SA, Harris TB. Association of long-distance corridor walk performance with mortality, cardiovascular disease, mobility limitation, and disability. JAMA. 2006; 295(17):2018-26. [PMID: 16670410]

50. Writing Group for the Activity Counseling Trial Research Group. Effects of physical activity counseling in primary care. The Activity Counseling Trial: A randomized controlled trial. JAMA. 2001;286(6):677-87. [PMID: 11495617]

Submitted for publication March 5, 2007. Accepted in revised form July 11, 2007. 